\title{
AN ANALYSIS OF NIGERIA'S NATIONALLY DETERMINED CONTRIBUTION (NDC) IN THE TRANSITION TO A LOW CARBON ECONOMY
}

\author{
Okoh, A. I. S.
}

Department of Political Science, Benue State University Makurdi, Nigeria.

Phone: 07087237879 Email: sadiqok4u@yahoo.com

\begin{abstract}
This paper examines the complexity of achieving economic growth simultaneously with low carbon transition in Nigeria. Nigeria's Nationally Determined Contribution (NDC) seeks to carry out far-reaching cuts capable of reducing the scale of pollution recorded in the country. But the ratification of the agreement also works at cross-purposes with Vision 20:20 and the Economic Recovery and Growth Plan (ERGP) since these development blueprints are heavily reliant on fossil fuels. Qualitative data was used to arrive at the study's' findings, complemented with quantitative data based on Nigeria Energy Calculator modelling tool for analyzing energy demand and supply in the country. The paper observed that a plethora of issues were impediments to the implementation of the NDC. That, fossil fuel energy generation as palliative is incapable of addressing issues of externality. Thus, Nigeria needs a new socio-economic contract termed the Food Sufficiency Economy (FSE) to usher in a net zero carbon trajectory. FSE is a convergence of food sovereignty and sufficiency economy. It is also in line with Africa's eco-bio-communitarianism perspective, but slanted towards Climate-Smart Agriculture as the building block for a low carbon and climate resilient future.
\end{abstract}

Keywords: biomass, climate-smart agriculture, food sufficiency economy, low carbon, NDC, renewable energy

LICENSE: This work by Open Journals Nigeria is licensed and published under the Creative Commons Attribution License 4.0 International License, which permits unrestricted use, distribution, and reproduction in any medium, provided this article is duly cited.

COPYRIGHT: The Author(s) completely retain the copyright of this published article.

OPEN ACCESS: The Author(s) approves that this article remains permanently online in the open access (OA) mode.

QA: This Article is published in line with "COPE (Committee on Publication Ethics) and PIE (Publication Integrity \& Ethics)". 


\section{NIGERIA'S INDC AND LOW CARBON TRANSITION}

Nigeria is a party to the United Nation's Conference on Climate Change (UNFCCC) which entered into legal force on 4th November, 2016 when 55\% of the global emitters and over 55 countries who are the major emitters ratified the accord. As a party to the UNFCCC, Nigeria acceded to significant reduction of greenhouse gas emission by placing the economy on a low carbon trajectory. However, fossil-led growth is the prevailing path towards transforming the economic fortunes of the country. This owes to her abundant fossil energy reserve. Nigeria is a major oil producing country with proven crude oil reserve of 37.2 billion, the country has the world's seventh largest gas reserves, with 187 trillion cubic feet (TCF) of high-quality proven reserves (Sambo, 2009; Cervigni, Rogers \& Henrion, 2013; Okoh, 2017).

According to a study commissioned by the World Bank in 2007, the country accounts for roughly one-sixth of the world-wide gas flaring, which, in turn, spews some 400 million tons of carbon dioxide into the atmosphere (Paehler, 2007; Okoh, 2014). The country gas flaring is equal to 40 percent of all Africa's natural gas consumed in the year 2001 alone (Koblowsky and Speranza, 2010; Okoh, 2014). The situation is further aggravated by deforestation with rural dwellers dependent on traditional biomass for domestic purposes (Bala, 2013a, Adebisi, 2013; Eleri \& Yahaya, 2014; Okoh, 2017, Oyewo, Aghahosseini, \& Breyer, 2017). Nigeria's vast quantities of fossil resources are expected to catalyze growth in the process leapfrog from low middle-income economy to the high middle-income economy by 2020. Nigeria's vision for the power sector is to harness her abundant fossil potentials to support socioeconomic transformation of the country. But the source meant to ensure economic growth also carries within it seeds capable of undermining growth as it is greenhouse gases (GHG) intensive. Hence Nigeria's journey to a green future will be undermined not only by climate-related extreme events, but her consequential gas flaring (Department for International Development [DFID], 2009; Federal Government of Nigeria [FGN], 2015; Bertheau, Cader \& Blechinger, 2016).

Far more critical, the Vision 20:2020 roadmap and the Economic Recovery and Growth Plan (ERGP) of 2017-2020 all seek to stabilize the macroeconomic environment by aligning monetary, trade and fiscal policies, accelerate non-oil revenue generation, drastically cut costs and privatize selected assets. The challenge Nigeria faces is how to generate sufficient electricity to promote economic growth. Overcoming this crisis is one of the main areas of focus of the ERGP as it is with short term outlook. Although the plan reiterates support for inclusion of renewable energies in the energy mix, it is detached from any midterm plan for the future energy mix that takes into account the relative costs and benefits of different options for economic recovery of the power sector (Roche et al., 2017). Similarly, Vision 20:2020 which is the development blueprint of the country is targeted at transforming the country by 2020 with fossil energy acting as a driver of economic growth (Adebisi, 2013; Bala, 2014; Cervigni et al., 2013; Roche et al., 2017).

Nigeria's journey to a net zero carbon emission trajectory presents a dilemma likened to the classic catch-22 scenario. The catch -22 playing out in Nigeria are: What are the effects of the NDC on the transition to zero carbon economy? Is Nigeria's NDC in line with the national development policy? What are the factors militating against

effective implementation of the NDC in the post-Paris era? How can the country transition to a zero-carbon economy without sacrificing economic growth? This paper examines the complexities surrounding Nigeria's dilemma of 
insisting on environmental protection while simultaneously maintaining a steady growth targeted at elevating the country to a developed economy.

To do justice to the issue, the paper comprises five chapters. The preceding chapter is the introduction. In the second chapter materials and methods are presented. Climate governance in Nigeria is the third chapter while constraint to the NDC implementation is the fourth section. This is closely followed by discussions of the NDC, energy status and implementation projections before arriving at our recommendations and conclusion for transitioning to a low carbon economy marks the final section.

\section{MATERIALS AND METHODS}

This study relies on Nigeria Energy Calculator (NECAL2050) designed by the Energy Commission of Nigeria based on International Atomic Energy Agency (IAEA) formulated analytical modelling tools of Model for Analysis of Energy Demand (MAED) and Model for Energy Supply Strategy and General Environmental (MESSAGE) impacts, for the analysis of energy demand and supply. NECAL2050 is an energy planning tool developed to relate the longterm energy demand and supply pathways to greenhouse gas emissions up to the year 2050. This gives quantitative insights into Nigeria's energy demand and supply enabling us to combine it with qualitative analysis to arrive at the effectiveness of Nigeria's NDC in charting a new pathway to an ecologically stable polity in the post-Paris era. Findings on the challenges and hopes of limiting carbon emissions to below $1.5^{\circ} \mathrm{C}$ temperature are presented and discussed before arriving at a synthesis for constructing an alternative roadmap to Nigerian-owned green growth and climate resilient policy.

\section{GREEN GROWTH GOVERNANCE IN NIGERIA}

Nigeria desire is to be amongst the first 20th developed economies in the world by 2020. The country's fossil fuel industry is critical to the transition from low middle-income economy to high middle-income economy. Nigeria is locked into a fossil dependent future with gas flaring contributing to global warming (Paehler, 2007). Yet, the country recorded remarkable growth within the last decade (Okoh, 2015a). The World Bank in 2013 foresaw a very bright future for the economy projected to grow by 6-7 \% 2013 and 2014 but was derailed by 2012 floods (Okoh \& Abuh, 2014). Oil production is one of the major sources of this growth with agriculture contributing $42 \%$ of the GDP (Okoh, 2015b). However, the gains of macro-economic growth recorded and also projected by the World Bank has been eroded by security challenges, rising unemployment, failing infrastructure, dwindling revenue from the oil and gas sector and climate extreme events. Rising incidence of climate change is a threat to government's Agricultural Transformation Agenda (ATA); National Agricultural Resilience Framework (NARF); Vision 20:2020 and the ERGP (Adebisi, 2013; FGN, 2015; Okoh, 2017; Roche et al., 2017).

All these mechanisms owe one thing in common: increasing investment in the energy sector. Thus, energy plays a vital role across all sectors in the economy in reducing GHG emissions. This is in line with the Cancun Decisions of the UNFCCC that addressing climate change requires a paradigm shift towards building a low-carbon society that offers substantial opportunities and ensures continued high growth and sustainable development, based on innovative technologies and more sustainable production and consumption and lifestyles, while ensuring a just transition of the workforce that creates decent work and quality jobs. 
However, most of the investments in the energy sector are fossil energy related. Investment in the fossil sector targeted at bringing about economic recovery also carries with it seeds of economic degeneration, that is, if not properly managed. Within the sector, government intends to use for the economic recovery lies a major outlet of ecological contagion. Herein lies the rub: building resilience of the poor to cope with increasing climate variability in a complex environment extensively dependent on crude oil for foreign exchange or strive to make the country's economic growth based on crude oil exploration to be ecologically neutral.

Although government signed the Kyoto Protocol in 1994, and ratified the Kyoto Protocol in 2004 as a NonAnnex 1 signatory, progress towards the implementation of the Protocol within the last window (2008-2012) was slow. Nigeria as Non-Annex 1 country was not required to take any action in curtailing emission of greenhouse gases. But Nigeria was obliged to issue four key National Communications; four in depth review summaries; a progress report; a National Adaptation Strategic Plan of Action (NAPA); and a Global Climate Observing System Report (Building Nigeria's Response to Climate Change [BNRCC], 2011). Government met some of these commitments and took various actions to limit climate change threats such as submitting the First and Second National Communication to the parties to the Kyoto Protocol; established the Climate Change Special Unit with Nigerian Meteorological Agency charged with research and climate observation and also sent three satellites to help monitor the climate. Equally, it initiated and passed the Petroleum Bill but the National Climate Change Bill is still inconclusive. Similarly,

the National Policy on the Environment (NEP) calls for energy efficiency in consumption and production of power. It insists on paying proper attention to renewable energy derived from solar, wind, hydro and biomass capable of fostering controlling emissions of GHGs.

Nigeria as a party to UNFCCC has technically acceded to Paris Agreement. The NDCs aims to promote sustainable development, while delivering on government priorities. Government's policies and measures are targeted at reducing poverty, increase social welfare as well as improving individual well-being, which includes a healthy environment. But by not undertaking adaptation measures, Nigeria could incur significant adaptation costs from exacerbated climate change. However, mitigation and adaptation to climate change is of immense importance to Nigeria in the post Paris era. Building the resilience of the poor to increasing climate variability is the most significant climate challenge facing the country. Though adaptation strategies to climate change are enshrined in Vision 20:2020, Transformation Agenda 2011 - 2015, National Adaptation Strategic Plan of Action (NASPA), the First National Communication (FNC) in 2003, Second National Communication in February 2014 and a host of other policies, implementation shortfall is posing a serious impediment to embarking on a low carbon trajectory.

To ensure an effective national response to the multi-faceted impacts of climate change, Nigeria should adopt a comprehensive strategy. This will promote low-carbon while ensuring economic growth in doing so build a climate resilient society.

\section{BARRIERS TO IMPLEMENTATION OF NIGERIA'S NDC}

The implementation of the NDC while also ensuring economic growth is a paradox with different forces pulling at opposing ends. However, as a party to the United Nations Framework Convention on Climate Change (UNFCCC) Nigeria is committed to binding cuts with serious consequences for its carbon-based economic system. Although the clean energy transition is not all about decarbonization and reduction in fossil consumption and production alone, it 
has immense benefits as a vital component of Bioenergy production can create employment in rural areas, contribute to foreign exchange savings, and reduce dependence on oil as the primary source of revenue. Still, the transition to a clean energy future is a complex issue with a portfolio of constraints posing serious barriers to building of a green society. These barriers to the implementation of net zero emission includes:

Energy Poverty- A major reason for the complex energy transition is the population of the country at 170 million and of this over 92 million live without electricity (Okoh, 2017). Nigeria is sparsely populated hence building electricity grids across long distances to reach communities living on less than $\$ 4-\$ 5$ a day does not make economic sense. Given this, there is widespread energy poverty with most rural communities not linked to the national grid.

Fossil dependency- Devolution of clean technology and fossil fuel dependent economic system will create significant transformations in the form of employment opportunities for different sectors of the economy. Nigeria is reliant on crude oil to grow the economy. Yet, the fossil fuel dependent economy has perilous ramifications for economic growth. Inasmuch as the economy is extensively dependent on a single resource, factors reordering priorities toward adverse pollution will prevail. With the stiff opposition from fossil fuel industry, the deployment of renewable energy will take place at the same time with increases in fossil fuel consumption and production evident in the 2016 and 2017 Appropriation Bills.

Biomass economy- Biomass sector is critical to all de-carbonization processes in most rural communities since biomass is the dominant energy source. Making the predominantly rural population transit to eco-friendly technologies will have disruptive implications for their livelihoods. In the absence of an appropriate policy framework, the current deployment of biomass-based energy will in the long run exacerbate deforestation, flood, and inadequate replacement of tree cover, soil erosion, and conversion of cropland to biofuels in addition to other agro-ecological contradictions. Finding an appropriate long-term regulatory measure and energy mix with the view to favorably exploring the country's vast biomass potential will require new energy optimization policy that emphasize energy efficiency and clean technologies while still ensuring food security.

Price of renewable- Cost is a major constraint to bridging the energy poverty gap. The country's vast biomass potential is largely untapped as a result of the difficult terrain making the implementation of clean energy technology still very expensive. Though prices of renewable are falling globally, it is still above what the country can afford. But when compared with the long-term co-benefits of renewable, such cost dwindles in significance. An example of untapped potential due to cost constraint is in hydropower. Hydropower potential alone is estimated to be $1852 \mathrm{TWh}$ per year, three times more than the country's current demand of 554TWh per year (Bala, 2013). Yet, about 58 per cent of the population lack access to electricity, while about 65 per cent lack access to clean energy for cooking. Similarly, other sources of renewable energy such as wind, hydropower and solar are unexplored. Even where renewable energy is minimally generated, the technology is still very expensive.

Water and food insecurity- Finding an appropriate long-term regulatory measure and energy mix to favorably explore the country's vast clean energy potential will require new policies emphasizing efficiency in water and food production. There is severe agro-fuel complex with food security and food sovereignty imperatives encouraging land 
grabs (Okoh and Mailumo, 2016). If the current land grab is allowed to persist, Food/fuel crops contradictions as bioenergy will compete for food crops as feedstock. An example is in Benue, Nassarawa and Kwara states where large swathes of land are grabbed for future plantations for sugar cane and cassava farms used as feedstock in biofuel production. These large-scale land acquisitions for farms are not only competing for land and are using arable land where stable food crops used for feedstock production will be pushed far beyond the reach of the poor.

Policy inconsistency- Government plays crucial role in resolving energy security impediments by redirecting policy and formulating institutional frameworks for deployment of clean energy. Political commitment and support of government gives policy direction for the development of necessary regulatory instruments for advancement of Paris climate Accord. Conducive policy instruments are vital components of clean development. Institutional bottlenecks are barriers to sustainable energy management and devolution of clean technology. Hence all stakeholders must be carried along to attain a socially inclusive green growth. But for now, policy inconsistency has impaired attainment of clean energy objectives of governments. Given the policy inconsistency, there are contradictions between the NDC's high claims and the 2016 Appropriation Bill. This explains why, despite acceding to the global decarbonization goal, the 2016 budget committed more resources to energy security most especially in a fossil-based power generation with a significant amount earmarked for renewable energy.

Governance Deficit- Pollution is mostly the product of externality by one economic agent on another not captured through the market (Okoh, 2017). Not all policy shortfalls are the outcome of market failure foisted as a result of inappropriate market mechanisms to address environmental externalities. Rather, it is mostly linked to nature and perception of the state. Nigeria is a neo-patrimonial state where insatiable rent seeking preoccupation of the political class is the driving force for the failure to institutionalize appropriate building blocks for a low carbon climate resilient economy to take root. A good example of clean energy vision derailed by the neopatrimonial character of the state is in the handling of clean energy stoves. In October 2014, the FEC awarded a contract for N9.2 billion worth of cooking stoves and wonder bags for rural women under the National Clean Cooking Scheme (Okoh, 2017). In the contract, it was agreed 750,000 units of clean stoves and 18,000 units of wonder bags were to be supplied by the designer from South Africa. The scheme was expected to have a lifespan of 5 years for the provision of 20 million stoves.

Environmentally speaking, this is sound reasoning as biomass extraction would have drastically dwindled. In addition, this policy has the co-benefit of not only creating jobs when assembled locally and would have environmental benefit in the form of carbon offsets thereby earning carbon credit for the country. But with the Prebendal politics of the previous administration, accumulation of both wealth and power was the order of the day. Although, the project has taken off, it is straddled with all sorts of controversies. What has emerged is that corrupt practices have stalled distribution of clean stoves. It will be misleading to attribute the failure to provide clean stoves to rural women on market imperfection rather, governance deficit is the bane and the problem.

Lack of Political Support- Post-Paris framework lacks local anchorage and the much-needed political support for limiting emission at the local level. Theoretically, the INDC is a bottom-up approach. In reality, was crafted by technocrats and NGOs with little inputs from the society. Since the instrument crafted on de-carbonization lacks local 
anchorage, it forebodes grave danger to the environment. Not only will it impede political lock-in in the NDC but will make it difficult at the individual level to integrate smallholder farmers into the national initiative.

Data Transparency- There is the dearth of accurate carbon emissions data to effectively reflect the country's carbon footprint. Capacity to accurately paint in objective terms the environmental pollution generated in all sectors is doubtful. Most of the projections in the INDC are based on estimates, making it difficult to ascertain these high-level claims. The lack of publicly available and transparent data supporting government claims will undermine commitment to Paris Agreement.

Equity- The binding commitment in Paris contravenes the principle of Common but Differentiated Responsibility enshrined in Agenda 21. Although Nigeria pledged to limit emission, conflict exists between national transformation agenda and the global de-carbonization framework which has exacerbated the energy poverty gap. Structural crisis exists at different levels acting as an impediment to efficient capping and monitoring of carbon emission. On one hand is the problem redistributing emission budget to address consumption and production of carbon for different individual, communities and states at different stages of growth. While at another level is the crisis of rebalancing growth towards net negative emissions in an unequal national polity with varied significance for different actors and sectors.

\section{DISCUSSIONS OF THE NDC, ENERGY STATUS AND GREEN ECONOMY IMPLEMENTATION PROJECTIONS}

Though the Nigerian economy recorded impressive growth in the last ten (10) years at the average rate of 6-7\% annually (Federal of Statistics, 2014) it is exogenously driven heavily reliant on a single resource: crude oil. Growth with extraneous determinant carries with it the seeds of further despoliation of nature wherein energy shocks at international level can exacerbate pollution. With the political space highly dominated by exogenous influence which determines the nature and form of policies formulated, such policies will definitely be extroverted. An examination of the country's NDC, energy status and implementation projection alongside the development blueprints is carried out underneath with the view to ascertaining whether the journey to a low carbon economy has commenced in earnest or it is a journey to scarcity and ecological disequilibrium.

\section{CLIMATE CHANGE MITIGATION}

The strategic thrust of the 2017 the budget titled 'Budget of Recovery and Growth' is to ensure that the country's economic fortunes improve such that it disentangles from the recession and back on a path of sustained growth. To bring this to fruition, capital expenditure within the 2017 budget is N2.24 trillion, compared to N1.77 trillion in the 2016 Budget (Okoh, 2017). This is in line with the Nigeria Integrated Infrastructure Master Plan (NIIMP) which is the funding benchmark for the sector. The NIIMP insists that over the first five years the country will require to spend $\$ 23$ billion in power, of which \$14-16 Billion will be required to increase generation capacity from the current levels to $20 \mathrm{GW}$ by 2018 (Centre for Social Justice, 2016). Allocation to the Ministry of Works, Power and Housing within the period was inadequate to meet the NIIMP requirements. The present Administration corrected this with increased 
allocation to cater for infrastructural development. With the $24 \%$ increase over 2016 Budget, the government intends to carry out rapid developments in power, road and rail sectors.

Still, the NIIMP was not designed with climate change related issues at heart. With the deficiency in NIIMP's formulation, effective mitigation and adaptation through budgeted funding is less than the expected funding in the transition to a low carbon and climate resilient economy. This assertion is based on the higher upfront cost of energy efficient technologies and measures. But the Centre for social justice (2016) believes low carbon energy efficient projects would be cheaper over the full life cycle when compared to carbon intensive methods of producing and distributing energy. The government also acknowledges the role private sector should play in funding the NIIMP yet, is inadequate in achieving the NIIMP goals. The purpose of the privatization is to generate $\$ 16.4$ billion through sales of assets, improve on the infrastructure that will increase internally generated revenue. Effectively, the economy will be diversified with this diversification expected to be achieved by increasing locally produced goods that will promote exports to other countries.

In the ERGP articulation, there is the understanding government in the 21 st century ceases to be the omnibus provider of citizens' needs into a force that removes all impediments to the free flow of goods and services. Though the country has formulated different policies as an exit from fossil strategy, the deployment of renewable energy as an exit from carbon, the strategy has no clear-cut vision. Rather, the exit strategies are scattered in different blueprints such as the ATA, Vision20:202; Vision 30:30:30; Sustainable Energy for all (SE4ALL) Action Agenda National Renewable Energy Action Plan (NREAP); Rural Electrification and Implementation Plan (RESIP) and NEP. Hence, the de-carbonization drive is a broad theme involving diverse sectors working at cross purposes (Okoh, 2015b; CSJ, 2016).

Even then, it is business-as-usual as gas flaring is on the rise. A major reason is the absence of institutional backing for addressing adaptation needs of the people such as the formulation of a Low Carbon Growth Strategy or a Climate Change Bill. For instance, solar energy has been recognized as a mitigation strategy capable of reducing the negative carbon footprint of the country. But the activities targeting a low carbon growth are housed under different sectors with MDAs all jostling for control of the political space. Overall, inter-ministerial tussle stymied a zero-carbon growth, thereby eroding the existing policies efficacy. Even where such policies achieve minimal success, allocation in the 2016 and 2017 Appropriation Bills are insufficient to foster a clean energy transition, neither can it meet the country's obligation of improving energy efficiency by $20 \%$ unconditional leading to the provision of $13 \mathrm{GW}$ of renewable electricity to rural communities currently off-grid. At this rate of investment in the power sector, government cannot realize its vision 20:2020 neither can it foster the attainment of 30,000MW of power enunciated in the Vision 30:30:30 target.

The country fleshed out its INDC based on the National Climate Change Policy Response Strategy (NCCPRS) with an ambitious goal of reducing greenhouse gases by $20 \%$ unconditional and $45 \%$, conditional mitigation objectives with a target year of 2030 with the implementation period of 2015 to 2030 (FGN, 2015). In effect, Nigeria's GDP per capita emission which stands at 2,950 in 2014 will by 2030 increase to 3,964. Mitigation actions included in the INDC to a large extent implement or enforce existing policies or strategies. It is also acknowledged that an additional legislation and regulatory changes will be required if the country will meet its 
pledges. The country also promised to carry out an assessment of the changes required to the regulatory and legislative framework upon finalization of the INDC. Such pledge brings to the fore challenges bedeviling the Petroleum Bill which is still trailing the passing of the Nigeria's Climate Change Bill overburdened by socioeconomic interferences.

Sketching an appropriate regulatory framework based on the INDC is a Herculean task. Given the political horse trade from diverse groups undermining the aforementioned bills, there are bound to be implementation bottlenecks in the NDC. Reinforcement of constraints resulting from the weak and indefinite low carbon policies is indicative of the influence of the opposing forces pulling at net zero emission. Similarly, the 2016 and 2017 Appropriation Bills are targeted at capital expenditure in infrastructural transformation. Again, the declining revenue from crude oil means government's transformation agenda faces an uncertain future. This has not been helped by the ERGP which is a combination of fossil driven and renewable energy generation, Moreover, the Ministry of petroleum Resources which housed the cash cow promotes a carbon intensive production, consumption and service delivery economy. Hence the challenge is how to minimize or mitigate the carbon intensive nature of its operations and productions.

Consequently, the ability to propel society towards green growth wherein clean technology should usher in an era where temperature rises modestly is at risk. The narrow gain of de-carbonization is threatened by the reinvigoration of fossil-based power production as a bailout from Nigeria's economic shock. Although, the national de-carbonization process will proceed at different levels for different states, but the implication for climate stressed region like the North East and Niger Delta is that climate change will have severe effect on development reordering priorities towards low carbon growth. Nigeria's de-carbonization drive will require a drastic reduction of gases spewed from oil production and also biomass extraction and consumption. This will mean decreasing revenue from oil exports, the mainstay of the Nigerian economy. It will further imply reducing biomass extraction and consumption which is also the primary energy source. Finding an appropriate energy mix to navigate the energy politics at international arena while also mitigating climate change at national level should be the ultimate emission stabilization goal.

Accordingly, the country must make sure such policy does not stifle the economic growth potentials. It will require complementary policies formulated on abatement of the scourge and economic growth. In the 2016/2017 budgets, government accurately concluded that economic growth can be achieved through improvements in the manufacturing base, education, agriculture, entertainment, innovation and technology thereby reducing the country's crude oil dependency. They also accurately assume diversification through tapping its vast natural resources will limit reliance on oil export. Though such transformation policy has the goal of efficient utilization of its vast energy resources (Table 1), still, energy generation and the deployment of resources toward building new power plants and transformation based on neo-extractive mentality will lead to further degradation of the ecosystem. Effectively, government has only succeeded in supplanting one form of pollution for the other. 
Table 1: Fossil Energy Resources and Nuclear Energy Sources

\begin{tabular}{|c|c|c|c|c|}
\hline S/NO & Resources & Reserves & Production (2011) & $\begin{array}{l}\text { Domestic Utilization } \\
\text { (2011) }\end{array}$ \\
\hline 1 & Crude Oil & 37.2billion barrels & 0.721billion barrels & 0.097billion barrels \\
\hline 2 & Natural Gas & 187 Tscf & $3.100 \mathrm{Tscf}$ & $\begin{array}{l}83.0 \% \text {-Fuel, Industries, } \\
\text { re-injection etc. } 17.0 \% \text { - } \\
\text { gas flare }\end{array}$ \\
\hline 3 & Coal & 2.7 billion tonnes & 0 & Negligible \\
\hline 4 & Tar Sands & $\begin{array}{l}31 \text { billion barrels of } \\
\text { oil equivalent }\end{array}$ & 0 & 0.224 million tonnes \\
\hline 5 & Nuclear & Yet to be quantified & 0 & $\begin{array}{l}\text { 30kW experimental } \\
\text { nuclear reactor }\end{array}$ \\
\hline
\end{tabular}

Source: Bala (2013).

To stem such negative growth, biomass energy is critical to clean development with over $60 \%$ of the population dependent on it for domestic purposes (Eleri and Yahaya, 2014; Roche et al., 2017; Okoh, 2017). So, Nigeria's renewable energy sources are critical components of the energy supply in most communities (Table 2).

Table 2: Total Primary Energy Consumption in Nigeria (2011)

\begin{tabular}{lll}
\hline Energy Form & Consumption (TOE) & \% \\
\hline Hydropower & $592,338.50$ & $0.71 \%$ \\
Fuelwood & $54,539,027.42$ & $65.50 \%$ \\
Petroleum Products & $9,467,060.83$ & $11.37 \%$ \\
Coal & $4,833.79$ & $0.01 \%$ \\
Natural Gas & $18,663,720.08$ & $22.41 \%$ \\
Total & $\mathbf{8 3 , 2 6 6 , 9 8 0 . 6 2}$ & $\mathbf{1 0 0 . 0 0 \%}$ \\
\hline \multicolumn{2}{c}{ Source: Bala (2014). }
\end{tabular}

From Table 2, it is evident that traditional biomass is the primary sources of energy, hence the energy sector vital for green growth is evolving. This should be integrated into energy mix. However, natural gas accounts for $64.97 \%$ of the total commercial energy consumption (Table 3). The most competitive technologies for generating electricity from the options in the table are hydropower and natural gas all presenting costs of $\$ 0.05$ to $0.07 \mathrm{kWh}$ on average (Roche et al., 2017). Still, gas-powered electricity is more cost competitive due to the lack of investment in renovation of existing dams. 
Table 3: Commercial Primary Energy Consumption in Nigeria (2011)

\begin{tabular}{lll}
\hline Energy Form & Consumption (TOE) & $\%$ \\
\hline Hydropower & $592,338.50$ & $2.06 \%$ \\
Petroleum Products & $9,467,060.83$ & $32.95 \%$ \\
Coal & $4,833.79$ & $0.02 \%$ \\
Natural Gas & $18,663,720.08$ & $64.97 \%$ \\
Total & $28,727,953.20$ & $100.00 \%$ \\
\hline
\end{tabular}

Source: Bala (2013).

The 2016 Budget proposal seeks to stimulate the economy making it more competitive by way of focusing on infrastructural development; delivering inclusive growth; and prioritizing the welfare of the people. To meet this goal, the budget of N6.08 trillion is in line with the transformational goal of government but with revenue projection of N3.86 trillion will result in a deficit of N2.22 trillion. The budget while encouraging industries, commerce and investment to pick up, will in the long run trigger negative growth, if not properly managed. The immediate gains of youth unemployment and improvement in the living conditions of the extremely poor and vulnerable class will be upturned by long-term degradations of the environment. Inasmuch as government has placed high premium on fossil fuel power generation and extraction of natural resources for the economy to grow, agroecological contradictions will be heightened. With growing agro-ecological crisis and rising population, projection under business-as-usual growth scenario, consistent with strong economic growth of 5\% per year and demographic assumption (Table 4), Nigeria's emissions are expected to grow to around 900 million tonnes per year in 2030, which translates to around 3.4 tonnes per person above the 2.0 tonnes per deemed adequate to maintain the mean global temperature increase at below $2 \mathrm{C}$ threshold.

Table 4: Demographic assumptions

\begin{tabular}{llllllll}
\hline Parameter & $\mathbf{2 0 1 0}$ & $\mathbf{2 0 1 5}$ & $\mathbf{2 0 2 0}$ & $\mathbf{2 0 2 5}$ & $\mathbf{2 0 3 0}$ & $\mathbf{2 0 3 5}$ & $\mathbf{2 0 4 0}$ \\
\hline $\begin{array}{l}\text { Population } \\
\text { growth rate }\end{array}$ & 3.16 & 3.52 & 3.80 & 4.00 & 4.00 & 3.88 & 3.74 \\
$\begin{array}{l}\text { Number of } \\
\text { persons per } \\
\text { household }\end{array}$ & 5.2 & 5.60 & 5.60 & 5.40 & 5.20 & 5.00 & 4.00 \\
$\begin{array}{l}\text { Number of } \\
\text { households }\end{array}$ & 0.0 & 3.7 & 42.1 & 53.2 & 67.3 & 84.8 & 101.9 \\
\hline
\end{tabular}

Source: Bala (2013).

This is not tenable as it will not usher the country to the exalted status of the 20th most developed economy by the year 2020. The challenge facing government is how to reorder energy consumption within the country's biospheric means which is in line with a higher growth rate while also ensuring energy efficiency. Increasing rate of sectoral energy demand (Table 5) implies that to grow the economy will require higher energy consumption. 
Table 5: Projected Sectoral Energy Demand in Nigeria based on 7\% Growth Rate

\begin{tabular}{llllllc}
\hline SECTOR & $\mathbf{2 0 0 9}$ & $\mathbf{2 0 1 0}$ & $\mathbf{2 0 1 5}$ & $\mathbf{2 0 2 0}$ & $\mathbf{2 0 2 5}$ & $\mathbf{2 0 3 0}$ \\
\hline $\begin{array}{l}\text { INDUSTRY } \\
\%\end{array}$ & 13.81 & 28.92 & 37.01 & 40.75 & 44.69 & 44.69 \\
$\begin{array}{l}\text { TRANSPORT } \\
\%\end{array}$ & 30.80 & 27.62 & 24.56 & 22.92 & 22.27 & 21.62 \\
$\begin{array}{l}\text { HOUSEHOLD } \\
\%\end{array}$ & 30.80 & 27.62 & 24.56 & 22.92 & 22.27 & 21.62 \\
$\begin{array}{l}\text { SERVICES } \\
\%\end{array}$ & 6.13 & 5.30 & 5.39 & 5.72 & 5.78 & 5.49 \\
$\begin{array}{l}\text { TOTAL } \\
\text { (mtoe) }\end{array}$ & 32.14 & 49.92 & 76.45 & 112.67 & 158.95 & 224.54 \\
\hline
\end{tabular}

Source: Energy Commission of Nigeria (2008).

To be reckoned as one of the 20th largest economies based on a 7\% growth rate will minimally increase energy consumption but cannot usher the country to the coveted status of high middle-income country within the stipulated timeframe. Based on an optimistic Growth Scenario I using NECAL2050 modeling tool, the GDP will need to grow by an average of $11.5 \%$ p.a. with the manufacturing sector contributing $22 \%$ to GDP by 2030 from $4 \%$ in 2010 leading to Nigeria's transition from agrarian to an industrialized economy. For industrialization to really take root, projected sectoral energy demand based on $13 \%$ growth rate is the ideal scenario (Table 6) but will spew a total of $747.27 \mathrm{mtoe}$ of gases per year by 2030 .

Table 6: Projected Sectoral Energy Demand in Nigeria based on 13\% Growth Rate

\begin{tabular}{llllllc}
\hline SECTOR & $\mathbf{2 0 0 9}$ & $\mathbf{2 0 1 0}$ & $\mathbf{2 0 1 5}$ & $\mathbf{2 0 2 0}$ & $\mathbf{2 0 2 5}$ & $\mathbf{2 0 3 0}$ \\
\hline $\begin{array}{l}\text { INDUSTRY } \\
\%\end{array}$ & 13.81 & 27.91 & 40.87 & 51.91 & 62.89 & 71.39 \\
$\begin{array}{l}\text { TRANSPORT } \\
\%\end{array}$ & 30.80 & 26.78 & 23.24 & 20.86 & 18.55 & 16.51 \\
$\begin{array}{l}\text { HOUSEHOLD } \\
\%\end{array}$ & 49.23 & 38.46 & 28.84 & 21.26 & 14.08 & 8.95 \\
$\begin{array}{l}\text { SERVICES } \\
\%\end{array}$ & 6.13 & 6.86 & 7.05 & 5.97 & 4.48 & 3.15 \\
$\begin{array}{l}\text { TOTAL } \\
\text { (mtoe) }\end{array}$ & 32.14 & 59.45 & 10.97 & 202.74 & 387.52 & 747.27 \\
\hline
\end{tabular}

Source: Energy Commission of Nigeria (2008).

In the implementation of this BAU scenario, Nigeria is confronted with the task of efficiently redirecting the ship of state towards sustained economic growth while keeping within the bounds of the NDC. Herein lies the hub as carbon emission holds great potential for improving the economic wellbeing of the people. With the nexus between energy consumption and GDP growth evidenced in the 2014 GDP rebase (Okoh, 2014), carbon-based growth will continue to play a vital role as burning dead carbon provides industries and households with much needed energy to fashion out the basic necessities of life. Using the energy calculator, projected electricity supply by fuel type based on $13 \%$ economic growth rate will require fossil fuel total power generation of 315,158.0 MW by 2030 (Table 6) and renewable power generation of 63,032MW (Table 7). 
Table 7: Projected Electricity Supply by Fuel Type Based on 13\% Economic Growth Rate (MW)

\begin{tabular}{lllllll}
\hline & $\begin{array}{l}\text { 2009 } \\
\text { (Based Yr) }\end{array}$ & $\mathbf{2 0 1 0}$ & $\mathbf{2 0 1 5}$ & $\mathbf{2 0 2 0}$ & $\mathbf{2 0 2 5}$ & $\mathbf{2 0 3 0}$ \\
\hline Coal & 0.00 & 3352.9818 & 3352.9818 & $12,121.794$ & $14,011.266$ & $20,398.634$ \\
$\begin{array}{l}\text { Electricity } \\
\text { Import } \\
\text { Gas }\end{array}$ & 0.00 & 0 & 0 & 0 & 0 & 67727 \\
Hydro & 3803.00 & 13109.77 & 26426.06 & $49,996.468$ & $120,512.45$ & $164,306.85$ \\
Nuclear & 0.00 & 0.00 & 3599.995 & 7199.99 & 7199.99 & 7199.99 \\
Small hydro & 20.00 & 105 & 319.9 & 759.85 & 1660.05 & 3502.1 \\
Solar & 0.00 & 490.35 & 2543.303 & 6417.268 & 15969.94 & 39737.5 \\
Biomass & 0 & 0 & 5 & 30 & 65 & 100 \\
Wind & 0.00 & 23 & 36 & 41 & 47 & 54 \\
Supply & 5746.00 & $21,238.09$ & $47,490.24$ & $88,698.37$ & $171,597.69$ & $315,158.07$ \\
\hline
\end{tabular}

Source: Bala, 2014

Nonetheless, the biomass sector is the fastest growing sector. In Nigeria this sector is immature requiring an in-depth analysis of the technologies to be deployed and the feedstock type that would not compete with food crop thereby undermining their potentials to build a low carbon economy.

The country's potential to leapfrog into a greener economic future seems tangible if the country can tap its vast renewable potentials (Table 7). 
Table 8: Renewable Electricity Supply Projection in MW (13\% GDP Growth Rate)

\begin{tabular}{llllll}
\hline S/NO & Resource & Now & Short & Medium & Long \\
\hline 1 & Hydro (LHP) & 1938 & 4,000 & 9,000 & 11,250 \\
2 & Hydro (SHP) & 16.18 & 100 & 760 & 3,500 \\
3 & Solar PV & 15.0 & 300 & 4,000 & 30,005 \\
4 & Solar Thermal & - & 300 & 2,136 & 18,127 \\
5 & Biomass & - & 5 & 30 & 100 \\
6 & Wind & 10.0 & 23 & 40 & 50 \\
& All Renewables & 2025.18 & 4,628 & 15,966 & 63,032 \\
& All Energy Resources & $\begin{array}{l}\text { 8,700 (installed } \\
\text { Gen Capacity) }\end{array}$ & 47,490 & 88,698 & 315,158 \\
& \% of Renewables & $23 \%$ & $10 \%$ & $18 \%$ & $20 \%$ \\
& $\%$ RE Less LHP & $0.4 \%$ & $1.3 \%$ & $8 \%$ & $16 \%$ \\
& & & & \\
\end{tabular}

Source: Bala, 2014

To achieve this, a biofuel policy has been formulated with the Nigerian National Petroleum Corporation (NNPC) mandated to spearhead the drive. The Nigerian National Biofuels Programme was launched in August 2005. At present, biofuel power generation is minimal with power generation from rice husk 5MW in Ebonyi state as the major biofuel source while other biogas generation for heating and power generation development are ongoing (Okoh, 2017).

Nigeria's exploitation of renewables tends to give a different impression of the current decarbonization drive. It might seem government has not given high preference to renewable energies as it deserves. Some may argue government does not really want the transition to a low carbon economy to happen since renewable energy is not the central plank of the reform agenda (Eleri \& Yahaya, 2014). Rather, the focus is to provide fossil energy to fuel growth leading to job creation and poverty reduction, irrespective of the source of energy. Even then, solar energy has the greatest potential to contribute enormous amount of low carbon energy. The solar capacity of the country is in the region of $4-6.5 \mathrm{kWh} / \mathrm{m} 2 /$ day (Cervigni et al., 2013; Adebisi, 2013). Solar from PV technology in the country is in the range of 207,000 GWh per year (Cervigni et al., 2013; Roche et al., 2017; Mentis, Welsch, Fuso, Broad, Howells, Bazilian \& Rogner, 2015) if 1\% of the land area were covered with PV modules (Nigerian Energy Support Programme [NESP], 2015).

Again, there is no large-scale extraction of solar. Lately, 14 solar companies have signed solar Power Purchase Agreements (PPAs) at $\$ 0.11 \mathrm{kWh}$ with NBET in 2016. Again, series of controversies threaten the ability of these companies to meet the 13,000 MW of off-grid PV solar electricity to be put in place by 2030 in the Vision 30:30:30 seeing that only about 15MW of dispersed solar PV systems are on ground (Mentis, et al., 2015). Wind resource of energy are available at $2-4 \mathrm{~m} / \mathrm{s}$ at $10 \mathrm{~m}$ height considered low for wind farm electricity generation using conventional wind generations. At higher heights, greater wind speeds may be encountered, where reasonable 
electricity could be generated (Sambo, 2009; Adebisi, 2013). It is envisioned about 40MW of wind electricity would be needed by 2020 .

The inability to explore the vast solar potentials means that fossil fuel dependency will be higher than renewables. More so that carbon emission and economic growth are not just coterminous but axiomatic necessities. The critical issue in the years to come is how to rebalance priorities towards the welfares campaign promises of the present Administration against capping emissions obligation as stipulated in the NDCs. For sustainable energy management, government should have from the 2016 Budget put in place measures ensuring a smooth transition to an ecologically sustainable polity. Critically, there is the erroneous assumption creating an enabling environment for attainment of the de-carbonization objective of Paris Agreement can stifle socially inclusive economic growth agenda (Okoh, 2015b). This is against the backdrop of rising natural gas production at 3.100Tscf with high rate of $17 \%$ gas flared (Bala, 2013a). Similarly, deforestation is projected to triple by 2035 with biomass and waste still the primary energy source (Okoh, 2017).

Overall, in terms of cost comparison renewables are the most efficient source to deliver energy in the long run as their prices are projected to drop drastically by 2025 to make them more attractive than fossil fuels energy (IRENA, 2016). Nonetheless renewable are perceived as high-risk area owing to the uncertainties in this sector and also the cost of doing business in Nigeria. So, off-grid solar power generation will be the most reliable source of energy for many homes. Yet, there is little or insignificant standardization resulting in the proliferation of inferior technologies thereby eroding the narrow gains in power generation. Accordingly, natural gas due to it lower upfront costs will be far more attractive for public private partnership.

\section{ADAPTATION AND INDCs}

Nigeria is critically impacted by different climate risks of varied dimension. The DFID (2009) study indicates that if no adaptation action is taken, between 2-11\% of Nigeria's GDP could be lost by 2020. Similarly, the Post Disaster Need Assessment (PDNA) Report following the 2012 flood also stated that the total damage caused by the disaster amounted to $\$ 16.9$ billion, representing $1.4 \%$ of real GDP growth in that year (FGN, 2015). This is because agriculture is one of the sectors most sensitive to climate change. Under business-as-usual scenario, agricultural productivity could decline between 10 - 25 percent by 2050. In some parts of the North, the decline in yield in rain fed agriculture could be as much as 50 percent. This in turn would impact the GDP, reducing it by as much as 4.5 percent by 2050 even though the share of agriculture in GDP will decline from 40 to just 15 percent (Cervigni \& Roger, 2013).

Cognizant of these threats, government has taken different measures to supplement autonomous adaptation strategies of the people by complementing existing climate change mitigation efforts with diverse strategies. Projected temperature to 2050 indicates there is increased trend leading to higher incidence of rainfall impacting on progress made towards poverty eradication and sustainable human development in the Southern and North central regions. The impact of climate change manifest in the form of temperature increases in major cities leading to crop failures, flood, drought, soil erosion, deforestation and rising sea level. This is because agriculture is the mainstay of the economy with $80 \%$ of the population in agriculture-based industry and of this $70 \%$ depend directly on rain-fed agriculture (Adebisi, 2014, Okoh, 2015b) The rural poor constitute a substantial population of those who are reliant on the rain- 
fed agriculture. Most of these communities are faced with new challenges as they operate with limited resources in fragile environment sensitive to minor shifts in temperature and rainfall patterns.

Nigeria's National Adaptation Plan (NAP) encapsulated in the NASPA document informed the adaptation component of the INDC. Nigeria's NDC sets out thirteen sector-specific strategies, policies, programmes and measures. The NAP blueprint presents government key opportunity to integrate concerns and needs of the agricultural sectors and actors into broad national strategies and policies. The NDC also aim to facilitate consideration and integration of food security and agriculture concerns and perspectives into the NAP process. It also requires at the same time that elements for non-agriculture specialists to understand what the issues are and to enable agriculture stakeholders to better identify and understand the issues at stake in a mid/long term perspective and to empower them to participate efficiently in the process (Food and Agriculture Organization [FAO], 2016). Nigeria's NDC in the postParis era is targeted inter alia at the following adaptation measures:

- Building resilience of the people in the agro-ecosystems to ensure their capacity to provide ecosystem services,

- Ensure the integration of the agriculture sectors as well as food security and nutrition concerns in climate change strategies and policies

- Integrated strategy related to water management, land and natural resource management, rural development and social protection

Despite charting of an adaptation strategy to pave way for a climate resilient and low carbon growth, dwindling revenue made realization of this goal far more intricate. Consequently, the quality of life is still low, health prospects poorer, malnourishment widespread and unemployment acute. Inconsistencies in fiscal policies, lack of political will and support stymie the adaptation implementation. Whilst growing insecurity in the North Eastern region will exacerbate challenges the region is immersed. The major culprit as the present Administration fittingly points out is corruption which springs from the neopatrimonial character of the state. A remarkable improvement in GDP growth was recorded under the previous Administration, but the major beneficiary is a select few (Okoh, 2014). For the vast majority of the people, poverty is still widespread thereby eroding the slender gains of economic growth. For inclusive growth, the political commitment of Paris must embrace the livelihood assets of the people in manner that climate policy translates to climate action driven by the people not the 'fit-all' police handed down from the top.

\section{RECOMMENDATION AND CONCLUSION}

Paucity of accurate and timely information is the bane of Nigeria's transition to a carbon neutral future. There is the need for research and data collection to be consistent, accurate, or on a scale over time that is relevant to nationallevel planning. Government should designate a responsible agency or institution with authority to coordinate all issues of the NDC. As such should be an independent monitoring and evaluation unit with constitutional backing. The capacity to implement the NDC is limited, due to the lack of financial and technical resources for the attainment of the goals of Paris Agreement. So, climate finance is essential and so government must take advantage of the Climate Innovative Finance and Clean Development Mechanisms (CDMs) to combat climate change shocks. There must be synergic integration of the NDC with national development policy which dovetail into the NASPA and also linked to 
other international priorities such as the Sustainable Development Goals, Vision 20: 20202 and the ERGP thereby increasing climate resiliency of the people.

So, a zero-carbon emission is the ultimate goal in the post-Paris era if the country must attain a fossil free future. This will require going beyond the current energy/security regime to a new political architecture based on adaptation and sustainability requirement advocated in the Food Sovereignty Economy (FSE) posited by Okoh (2017). FSE is a convergence of ecologically sound principle borrowed from food sovereignty concept and sufficiency economy but with Climate-smart Agriculture imperative at heart. This approach is in line with Africa's biocommunitarianism world view where human ecological requirements are within their biophysical limits while ensuring eco-development through eco-efficiency.

Overall, Nigeria's clean energy future is taking shape with the fleshing out of the NDC. Nigeria's commitment is the baseline to monitor progress on the implementation of de-carbonization while also opening up new business opportunities in renewables. Different communities have embraced the de-carbonization and without government's leadership role. But this should not be. Government should play key role in ensuring synergetic integration of different adaptation approach into the national development policy and the standardization of the diverse devolution of clean technologies.

\section{REFERENCES}

Adebisi, A. (2013). Action Plan for the Large-scale Deployment of Renewable Energy Sources in Nigeria. A OneDay Sensitization Workshop and Public Presentation of the 2nd Edition of Renewable Energy Master Plan Organized by Federal Ministry of Power at Rockview Hotel, Abuja.

Bala, E. J. (2013). Energy and Sustainable Development in Nigeria: Issues and Prospects. Presentation made to Course 22, National Defence College of Nigeria, Abuja, Tuesday, 12th November 2013.

Bala, E. J. (2014). Status of Energy Access in Nigeria. Paper Presented at the Workshop on Energy Access and Village Inventory Organized by the World Energy Council, Johannesburg, 18th February 2013. Retrieved on $2^{\text {nd }}$ January, 2018 from http://www.energy.gov.ng/index.php?option=com docman\&task=cat_view\&gid=39\&Itemid=49

Bertheau, P., Cader, C., \& Blechinger, P. (2016). Electrification Modeling for Nigeria. Energy Procedia. AfricaEU Symposium on Renewable Energy Research and Innovation 93: 108-112. doi: 10.1016/j.egypro.2016.07.157

Cervigni, R., Rogers, J. A., \& Henrion, M. (Eds.) (2013). Low-Carbon Development Opportunities for Nigeria. Washington, DC: The World Bank

CSJ- (Centre for Social Justice). (2016). Budgeting for Climate Change in the Energy Sector. Retrieved on 3rd. January, 2018 from www.csj-ng.org

Eleri, E. \& Yahaya, A. (2014) Green Deal Nigeria? Stumbling Along the Road from Fossil Fuels to Clean Energy. In Heinrich Böll Stiftung (ed.), Greening the Continent: Reflections on low Carbon Pathways. South Africa: Heinrich Böll Stiftung. 
FGN- (Federal Government of Nigeria). (2015). Approved Nigeria's INDC Submision. Retrieved from www4:unfccc.int/submisions/INDC/submissionpages/submissions.aspx

Energy Commission of Nigeria (2008). Retrieved on $2^{\text {nd }}$ January, 2018 from http://www.energy.gov.ng/index.php?option=com_docman\&task=cat_view\&gid=39\&Itemid=49

FAO- (Food and Agriculture Organization), (2016). Climate change and food security: risks and responses. Retrieved on 3rd January, 2018 from www.fao.org/publications.

IRENA (2016). The Power to Change. Solar and Wind Cost Reduction Potential to 2025.

Koblowsky, P. and Ifejika, C. I. (2010, 8-9 October). Institutional challenges to developing a Nigerian climate policy. Paper submitted to the 2010 Berlin Conference on the human dimensions of global environmental change, Social dimensions of environ mental change and governance, Berlin, Germany.

Okoh, A. I. S. (2015a). Examining the nexus of Corruption, Economic Growth and Poverty in the Democratic Governance of Nigeria. Africa Research Corps- Journal of Business and Economics 1,(1): 22-30

Okoh, A. I. S. and Abuh, G. A. (2014). 'The sustainability of Adaptation strategies in the Management of climate Extremes: A Case Study of Lower Benue in the 2012 Nigerian Floods'. A Paper presented at the Fourth Climate Change Development Africa Conference (CCDA-4) Organized by UNECA at Marrakesh, Morocco between 8th and 10th October, 2014.

Okoh, A. I. S. (2014). Green Economy Vs Green Growth: A Quest for an Ecologically Sustainable Polity in Nigeria. SCSR Journal of Development, 1(4): 22-40.

Okoh, A. I. S. (2015, 14-16 October). Can Clean Energy Transition (CET) save Africa from Energy Poverty? Paper presented at Nigeria Alternative Energy Expo held at Shehu Isa Yar-adua International Conference Centre, Abuja, Nigeria. Retrieved from www.nigeriaalternativeenergyexpo.org/index.php

Okoh, A. I. S., and Mailumo, D. A., (2016). Switching to Low Carbon Civilization: Towards an Eco-friendly Policy on Biomass. Africa Journal of Management, Social Science and Humanities, 5(1): 37-51.

Okoh, A. I. S (2017). Pathways to a Green economy in post-Paris Africa. Oxford: Green Economics publishing House.

Oyewo, S., Aghahosseini, A., \& Breyer, C. (2017). Assessment of Energy Storage Technologies in Transition to a 100\% Renewable Energy System in Nigeria. Available at: 11th International DFID- 11. (Department for International Development (2009). Impact of Climate Change on Nigeria's Economy. Final Report. February 2009.

Paehler, K. (2007). Nigeria in the Dilemma of Climate Change. . Retrieved February 12, 2016, from http://www.kas.de/proj/home/pub/33/2/dokument_id-11468/index.html

Roche, M. Y., Ude, N., and Ofoegbu, I. (2017). True Cost of Electricity: Comparison of Costs of Electricity Generation in Nigeria. A Report of Heinrich Boll Stiftung/The Nigerian Economic Summit Group. 
Sambo, A. S. (2009). Strategic Developments in Renewable Energy in Nigeria. International Association for Energy Economics, Third Quarter.

Nigerian Energy Support Programme [NESP], (2015). Retrieved on $2^{\text {nd }}$ January, 2018 from https://www.giz.de/en/../giz2016-en-promoting-clean-energy-investments-in-nigeria. 